\title{
EDITORIAL
}

\section{Spinal muscular atrophy, pediatric virology and gene therapy: A challenge of modern weakness and hope}

\author{
BASIL T. DARRAS ${ }^{1}$, IOANNIS N. MAMMAS ${ }^{2}$ and DEMETRIOS A. SPANDIDOS ${ }^{2}$ \\ ${ }^{1}$ Department of Neurology, Harvard Medical School, Boston Children's Hospital, Boston, MA 02115, USA; \\ ${ }^{2}$ Department of Clinical Virology, School of Medicine, University of Crete, 71003 Heraklion, Crete, Greece
}

Received December 20, 2017; Accepted February 7, 2018

DOI: $10.3892 /$ etm.2018.5883

\begin{abstract}
Spinal muscular atrophy (SMA) type I is a devastating diagnosis for 'the smiling infant, who progressively develops weakness, hypotonia and respiratory distress, related to respiratory failure and life-threatening infections caused by common pathogens' (1). These pathogens include bacteria and various viruses, such as respiratory syncytial virus (RSV) and seasonal influenza viruses. Despite the fact that there

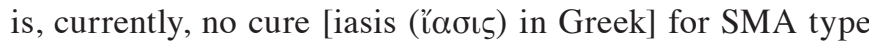
I, it does not mean that that there are no therapeutic options [therapia $(\theta \varepsilon \varrho \alpha \pi \varepsilon i ́ \alpha)$ in Greek] and hope $(2,3)$. There are several paths the families of the affected children can follow, depending on the country they live in and the medical specialized services that can be offered to them. These options aim at managing symptoms, reducing the complications of muscle weakness and maintaining optimal quality of life. One of the options is non-invasive ventilation, which 'when combined with nutritional support, can indeed prolong survival' (1); the use of invasive ventilation remains controversial. In several countries worldwide, it is currently possible to access a new therapeutic intervention for SMA, a drug named Nusinersen, also known as Spinraza ${ }^{\mathrm{TM}}$. The child's parents/guardians and the child's medical team are expected to come to a decision as to its potential benefit for their child with SMA type I. In the meantime, there is ongoing research in leading worldwide centers, such as the Boston Children's Hospital in Boston (MA, USA), with hope that this research will lead to other treatments for SMA (4).
\end{abstract}

Correspondence to: Professor Demetrios A. Spandidos, Department of Clinical Virology, School of Medicine, University of Crete, 71003 Heraklion, Crete, Greece

E-mail: spandidos@spandidos.gr

Key words: spinal muscular atrophy, SMA type I, pediatric virology, gene therapy, viruses
Thus, at the moment, the question remains as to which path is the optimal choice for a child newly diagnosed with SMA type I based on evidence-based medicine. This is a very difficult 'personal decision, depending on parental preference' (1). A decision though, which accepts the weakness of modern medicine and brings to our mind the Hippocratic saying, which asks medical physicians 'not to interfere in cases, where the patients are completely defeated by their illness, knowing that medicine does not have the power to do everything' [xaì

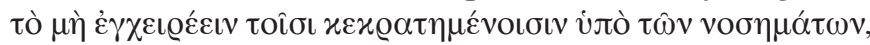

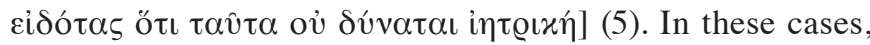
almost even 2,500 years ago, the quality of life seemed to be the principal value instead of endless interventions, invasive treatments and surgical options that lead to nowhere. Hippocrates (Island of Kos, $460 \mathrm{BC}$ - Larissa, $370 \mathrm{BC}$ ) is the same, who in his Oath denies with emphasis euthanasia saying that medical physicians 'should never give to their patients drugs leading to death, or relevant advice, even if they are asked to do so' [où

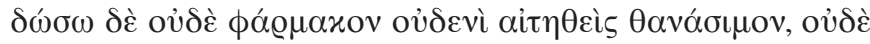

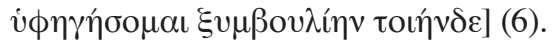

A future intervention may involve gene therapy. "Gene therapy using viral vectors is expected to offer an 'one and done' therapy and possibly cure the disease if administered early in life before symptoms appear" (1). What is of great interest is that 'viruses, which at the moment can be the cause of death in these children, with proper genetic engineering, could be used for their treatment in the future' (1). Our current weakness has to make us stronger, while waiting and endeavoring into the future with hope for an eventual cure or full prevention for one of the most devastating diseases of modern medicine. In addition, as it is also noted in our interview, which is dedicated to the memory of our young patient from Greece, 'the cure of SMA does not seem as far into the future as it looked 5 or 10 years ago' (1).

\section{References}

1. Mammas IN and Spandidos DA: Spinal muscular atrophy type I and the dual role of viruses: An interview with Professor Basil T. Darras, Professor of Neurology (Pediatrics) at Harvard Medical School. Exp Ther Med (In press).

2. Darras BT: Spinal muscular atrophies. Pediatr Clin North Am 62: 743-766, 2015 . 
3. Darras BT, Monani UR and De Vivo DC: Genetic disorders affecting the motor neuron: Spinal muscular atrophy. In: Swaiman's Pediatric Neurology: Principles and Practice. Swaiman KF Ashwal S, Ferriero DM, Schor NF, Finkel RS, Gropman AL, Pearl PL and Shevell MI (eds). Elsevier, pp1057-1064, 2017.

4. Spinal Muscular Atrophy Program: Research and Innovation. http:// www.childrenshospital.org/centers-and-services/spinal-muscularatrophy-program/our-innovative-approach.

5. Hippocrates: On art (Peri tehnis). In: Hippocrates, Apanta 1. Cactus Editions, Athens, 1993 (In Greek).
6. Hippocrates: Oath (Orkos). In: Hippocrates, Apanta 1. Cactus Editions, Athens, 1993 (In Greek).

(i) (9) This work is licensed under a Creative Common EY NC ND Attribution-NonCommercial-NoDerivatives 4.0 International (CC BY-NC-ND 4.0) License. 